\title{
A Trial of Implementing Engineering Education for Undergraduate Students in Optoelectronic Major
}

\author{
Yifan Huang \\ School of Optoelectronics \\ Beijing Institute of Technology \\ Beijing, CHINA \\ huangyifan@bit.edu.cn
}

\author{
Qun Hao \\ School of Optoelectronics \\ Beijing Institute of Technology \\ Beijing, CHINA \\ huangyifan@bit.edu.cn
}

\author{
Yao $\mathrm{Hu}$ \\ School of Optoelectronics \\ Beijing Institute of Technology \\ Beijing, CHINA \\ huangyifan@bit.edu.cn
}

\begin{abstract}
The paper describes how the engineering education was implemented at School of Optoelectronics of Beijing Institute of Technology, Beijing, China. In order to improve the engineering ability of the undergraduate students, we designed an engineering training plan and developed a curriculum including 6 college-enterprise cooperative courses and a 6months graduation project in the industries. The teaching design, the implementation methodologies, experiences and results were introduced.
\end{abstract}

Keywords-Engineering education; college-enterprise cooperative curriculum; teaching design; graduation project

\section{INTRODUCTION}

Engineering education is becoming a discipline [1] or at least a field of scientific inquiry [2]. It is also posited that engineering education is a discipline and a professional activity [3]. For engineering educators to distinguish themselves as a profession they must meet the three criteria of: the existence of a common body of knowledge that defines expertise, expectations of behavior that distinguish one from others in society broadly, and ethical standards [4-8].

In recent years, engineering education has been paid more attention in Chinese universities of science and engineering. The main reason is that traditionally engineering education in China is detached from or lags behind the rapidly growing industry, and the connection between enterprises and universities is not close enough.

As China has been making great efforts to transform from a big to a powerful country in technology, Industries has put forward an urgent demand to universities for fostering quality engineers. In order to meet their needs, a teaching project named "Engineers Training Plan (ETP)" has been implemented to the undergraduate students at School of Optoelectronics, Beijing Institute of Technology since 2011. The approach was motivated by the following factors: (1) to explore and develop a new engineering education mode for the students majored in optoelectronics; (2) to meet the huge local industry needs for optical engineers with strong practical solution abilities Aiming at these objectives, college-enterprise cooperative curriculum was designed, and real-world projects from industries are highly emphasized in the teaching process.

The paper will introduce how ETP was implemented. The following section of this paper is arranged as follows. Section II is the whole description of ETP. The detailed implementation methodologies are given in Section III. The feedback and discussion are present in Section IV, and we conclude our work in Section V.

\section{TEACHING DESIGN OF ENGINEERS TRAINING PlAN (ETP)}

\section{A. Teaching Objectives of the ETP}

The teaching objectives of the Engineering Training Plan focus on training the students in the following aspects:

- Understanding the basic theories in optoelectronic fields.

- Having the ability to analyze real-world optoelectronic system problems and make corresponding design proposal.

- Considering and working across disciplines (optics, mechanical, electronics, computer and software, etc.) on team work.

- Gaining working experience in industries.

Optoelectronics is a typical interdisciplinary major. It starts from basic mathematics and physics and the final objective is to develop creative and useful engineering systems. Optoelectronics related majors are with Chinese characteristics and can be regarded as a comprehensive major based on Optical Engineering, Electronical Engineering, Mechanical Engineering and Computer Science. The undergraduates in optoelectronics related majors are busy learning basic physical principles and mathematics in the first two years. So the time for them to convert the basic principles into engineering 
abilities is limited. ETP is both important and urgent, so we need a comprehensive design and implement.

\section{B. Teaching design of ETP}

The ETP was first implemented in 2011 and has been conducted for 5 years for undergraduate students majored in optoelectronics. Every year, we select about $30-40$ students to enroll in this plan, which accounts for about $1 / 4$ in all the students.

In the first 2 years, Students enrolled in this plan will have the same course curriculum as other students. It is because in our undergraduate training program, students should take most of the foundation courses in the first 2 years. For example, students majored in Optoelectronics will take Mathematics, Physics, Computer programming, Analog/Digital Electronic Technique etc. At the same time, they may be given some fundamental major course in optoelectronic fields, such as Geometric/Wave optics, optoelectronic technology, principles of laser technology. Based on the knowledge the students gained in the first 2 years, they will go more deeply in studying more major courses in the $3^{\text {rd }}$ and the $4^{\text {th }}$ year. In this stage, students in ETP will have some different arrangements.

ETP emphasizes on the industries' deeply involving in the teaching process. We designed a college-enterprise cooperative curriculum for the students (Shown in Fig. 1). Besides the necessary major courses and experiments given in our school, the students must take 6 college-enterprise cooperative courses. Furthermore, in the last 6 months of their 4-years undergraduate study, students in this plan must do a graduation project based on real engineering problems in the industries. The whole process will be administrated by both our schools and industries. Academic teachers and industrial teachers work together in the courses and the project supervising.

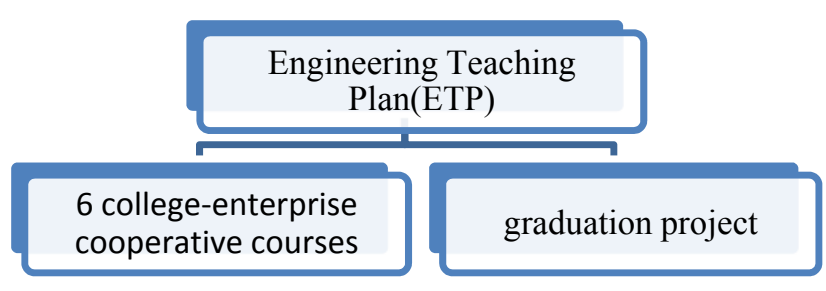

Fig. 1.Teaching design for ETP

\section{IMPLEMENTING METHODOLOGIES}

When implementing ETP, we established a joint education committee with industries. Every semester, the committee will hold at least 2 meetings, discussing the operable methods to promote the concrete cooperation on courses or projects.

\section{A. 6 Courses}

According to the basic education requirements for the Optoelectronic major from China's Ministry of Education, we selected 6 courses to perform college-enterprise cooperative teaching. The courses are shown in Table I.
TABLE I.

COLLEGE-ENTERPRISE COOPERATIVE COURSES

\begin{tabular}{|c|c|c|}
\hline No. & Course name & $\begin{array}{c}\text { Academic } \\
\text { Year\# }\end{array}$ \\
\hline 1 & Optical system designing and manufacturing & 3 \\
\hline 2 & Optoelectronic Display Technology & 3 \\
\hline 3 & $\begin{array}{c}\text { Fabrication Technology of Optoelectronic } \\
\text { Semiconductor Devices }\end{array}$ & 3 \\
\hline 4 & Modern Optical Thin Film Technology & 3 \\
\hline 5 & $\begin{array}{c}\text { Design and Simulation of Optical } \\
\text { Communications System }\end{array}$ & 4 \\
\hline 6 & Optoelectronic measuring technology & 4 \\
\hline
\end{tabular}

Brief introductions to the courses are as follows. Optical system designing and manufacturing focuses on the principle and method for optical design as well as the basic approaches for the realization of optical systems [9]. Typical optical systems include camera, telescope, microscope and etc. They are widely used in daily life and scientific fields. Optoelectronic Display Technology concerns the display principle and typical devices including liquid display, plasma display, light-emitting diode display and etc. Frontier techniques in this course include three-dimensional display, virtual reality display. The traditional display is an indispensable part of various systems and the novel techniques may change our daily life [10]. Fabrication Technology of Optoelectronic Semiconductor Devices tells about the fabrication techniques of $\mathrm{CCD}$ or $\mathrm{CMOS}$ detector, liquid crystal and etc. It is the basis of the above techniques. Modern Optical Thin Film Technology introduces the latest manufacturing technique, applications and testing techniques for optical thin film. Design and Simulation of Optical Communications System shows the basic principle of optical communications with optical fibers and further teaches the design and simulation method for it. Optoelectronic measuring technology introduces all the common testing methods for the above systems including the performance of imaging systems, display system, optical thin film, and also for length, shape and velocity.

In order to offer these courses for students, we established collaboration with several industries with optoelectronic professional background. For each course, a teacher from the school of optoelectronics and a skilled technician from industry were designated to be the responsible instructor. The responsibilities are as follows.

1) For School teacher:

a) Making the curriculum plan, discussing with the industry technician about the propotions for theoretical units and practical units.

b) Responsible for the theoretical units teaching at school, which mainly focus on the principles of the corresponding technology.

c) Evaluating the students' overall performance at the end of the course.

2) For industry technician:

a) Responsible for the practical units teaching in industry. 


\section{FEEDBACK AND Discussion} students.

b) Design and Instructing the actual operation for

c) Evaluating students' performance in practical operation.

Meanwhile, the practical parts of the courses take up more than $2 / 3$ of the whole units. With a combination of theories and practices, students can get a good balance between knowledge and skills through real operation in industries. After the course training, students can establish a basic sunderstanding about engineering.

\section{B. Graduation project}

Usually, undergraduate students in $4^{\text {th }}$ year need to do graduation project in China, which is indispensable for their degree application. The general way is that the students go to the universities' laboratories, participating in their teachers' research work. To some degree, it can help the students to know something about research. But it is still far from real engineering.

For ETP students, we require them to go to the industries to finish their graduation projects. Every year, each industry will give out 4-5 topics for the students, which are engineering projects from real production or research. Students can choose one topic on the basis of their interests. After that, students choosing topics from the same industry will form a team. They will have a common academic supervisor from school, who mainly give them advice for thesis writing. But each student will have an industry supervisor, who is responsible for the direct instructions during the whole process of graduation projects.

In about 6 months, students were arranged to industries to attend the real production process. They act just as technicians. The industry supervisor will instruct the students to participate in the problem analyzing, plan determination, researching and real manufacturing. In this procedure, students can have the opportunity to gain the fundamental skills of a real engineer.

The final grading for the students includes:

- Preliminary report.

- Intermediate design report.

- Final report (graduation thesis).

- Final presentation in front of the whole class and supervisors.

- Quality evaluations of their engineering project.

In the final presentation, every student is expected to present his work in the project and be able to answer questions about any aspect of the project. This encourages a sense of responsibility for the project.

The grading will be also based on team evaluations. Since teamwork spirits are very important for an engineer, we will ask students in the same team to grade their classmate. The results are important part of the final marks.
Every year when the students finish their undergraduate study, we will conduct a survey to obtain the feedbacks. Here are comments from some students:

- This is a very good experience and our practical solving ability was enhanced greatly.

- The experience in industry helps me make connection between books and practice.

- I like the project from industry. It tells me how to think and take measure in front of a real problem. I even feel I was an engineer!

- My hands-on skills were improved.

- I can gain much more through practice and experiments.

Also we got feedbacks from industries:

- Students enrolled in ETP have a good start in their professional career.

- After training, students can meet the basic requirements for an engineer.

- We welcome students in your school to work here.

From the feedback, we get a lot of positive results. But we are very clear that there is still much space left to be improved. The selection of projects, balance between guidance and selfdirected active learning, faculty experience and teaching resources are important issues to be considered next. We will try to make engineering education more scientific and efficient In this way, students can gain the knowledge and skills, which help them, transfer smoothly from universities to industries.

\section{CONCLUSIONS}

We proposed the necessity of engineering education in China and based on it we designed and implemented an engineering training plan and curriculum including 6 collegeenterprise cooperative courses and a 6-months graduation project in the industries at School of Optoelectronics of Beijing Institute of Technology, Beijing, China. After several years of trial, we have received positive feedback from both the student and the industry. We will continue working on it and make the engineering education better.

\section{REFERENCES}

[1] D. Radcliffe, "Shaping the Discipline of Engineering Education," Journal of Engineering Education, vol. 95, pp. 263-264, 2006.

[2] J. E. Froyd and J. R. Lohmann, "Chronological and Ontological Development of Engineering Education as a Field of Scientific Inquiry," in Cambridge Handbook of Engineering Education, A. Johri and B. M. Olds, Eds., ed New York: Cambridge, 2013.

[3] R. A. Cheville, and J. Heywood, "Drafting a code of ethics for engineering education," IEEE Frontiers in Education Conference, 1-4, 2015.

[4] Robert M. Bunch et al., "Rethinking optical engineering capstone design experience", Proc. SPIE, Vol. 7783, 2010.

[5] J. Heywood, Engineering Education : Research and Development in Curriculum and Instruction. New York: Wiley-IEEE Press, 2005. 
[6] J. Heywood and R. A. Cheville, "Is engineering education a professional activity?", presented at the American Society for Engineering Education Annual Conference, Seattle, WA, 2015.

[7] G. Report, "Report on evaluation of engineering education (reprint of the 1955 report)," Journal of Engineering Education, vol. 93, pp. 74-94, 1994.

[8] R. Korte, "The formulation of engineering identities: Storytelling as philosophical inquiry," in Philosophy and Engineering: Reflections on
Practice and Principles and Process, D. P. Michfelder, N. McCarthy, and D. E. Goldberg, Eds., ed Dordrecht: Springer, 2013.

[9] J. Burge and R. E. Parks, "Opto-mechanical engineering education at University of Arizona”, Proc. SPIE, Vol. 7424, 2009.

[10] Van Derlofske, J. F., "Computer modeling of LED light pipe systems for uniform display illumination," Proc. SPIE 4445, 119-129, 2001. 